\title{
PROJETO DE ARQUITETURA: PROCESSO ANALÓGICO OU DIGITAL?
}

\author{
Architecture design: analogic or digital procedure?
}

\section{Paulo Afonso Rheingant ${ }^{1}$}

RESUMO O artigo apresenta uma reflexão sobre a relação entre os processos analógico e ligital e uma discussão sobre os reflexos do uso e disseminação do computador como ferkamenta de comunicação dos arquitetos com proprietários, construtores e usuários fundamentada no entendimento de projeto como linguagem de comunicação e de ferramenta de concepção. Em lugar de discutir as vantagens e desvantagens do uso do computador em um projeto, uma questão superficial, recorre-se aos estudos de Bateson sobre a lógica das relações de duplo vínculo da comunicação humana e sobre o uso concomitante de dois modos de linguagem palavras (digital) e emoções (analógico) - para refletir sobre os riscos da perda da capacidade dos arquitetos no uso da linguagem analógica à medida que a tecnologia digital avança. Diante do risco de estarmos construindo uma barreira comunicativa decorrente da crescente dependência de uma lógica digital, argumenta-se em favor da necessidade enfatizarmos a importância do desenho como linguagem de comunicação analógica e digital, seduzidos pelas demandas crescentes de precisão e eficiência cujo preço pode vir a ser abrir mão de nossa humanidade.

PALAVRAS-CHAVE: Projeto de arquitetura, Processo analógico, Processo digital.

ABSTRACT This paper presents a reflection on the relationship between the analog and digital processes and a discussion on the consequences of the use and dissemination of the computer as a communication tool for architects with owners, builders and users based on the understanding of design as a communication language and design tool. Instead of discussing the advantages and disadvantages of computer use in design, a superficial question, we call upon Bateson's studies on the logic of the double bond of relationships of human communication and the concomitant use of two language modes - words (digital) and emotions (analog) - to reflect on the risks of loss of the ability of architects to use analogical language as the digital technology advances. Facing the risk of building a communicational barrier due to the increasing reliance on digital logic, we argue in favor of the need to emphasize the importance of drawing as a communication language that is both digital and analogic, seduced by the growing demands of accuracy and efficiency whose price might be giving up our humanity.

KEYWORDS: Architectural design, Analogic process, Digital process.

\section{How to cite this article:}

RHEINGANTZ, P. A. Projeto de arquitetura: processo analógico ou digital. Gestão e Tecnologia de Projetos, São Carlos, v. 11, n. 1, p. 95-102, jan./jun. 2016.

http://dx.doi.org/10.11606/gtp.v11i1.98382

Fonte de financiamento: Conselho Nacional de Desenvolvimento Científico e Tecnológico (CNPq) e Coordenação de Aperfeiçoamento de Pessoal de Nível Superior (Capes). Conflito de interesse: Declaram não haver. Submetido em: 21 maio 2015 Aceito em: 11 nov. 2015 


\section{PREÂMBULO}

No início era a própria obra. Com a representação gráfica, os desenhos à mão passaram a mostrar $o$ que o arquiteto projetava. Igrejas, palácios, grandes edifícios, cidades foram erguidos assim. Chegou o computador e fez-se o CAD (computeraided design). A princípio, muita desconfiança: a tecnologia mudaria a arte? Transformaria a forma de pensar? Os arquitetos não seriam mais artistas, mas homens mais próximos da tecnologia, súditos de um computador? Aos temerários, as respostas do tempo. Hoje são raros os arquitetos que não utilizam o computador para projetar.

(ANTUNES, 2011, p. 6)

Esta citação extraída do editorial da revista Arquitetura e Urbanismo de julho de 2011, de autoria de Bianca Antunes, resume com clareza o dilema sobre o uso e a disseminação do computador como ferramenta de projeto. Essa disseminação tem se refletido no ensino de projeto de arquitetura com a tendência crescente de substituir a tecnologia analógica pela digital no processo de concepção do projeto.

Essa tentativa tem provocado algumas inquietações relacionadas com sua natureza, que não se resume a uma simples substituição de uma tecnologia por outra, mas que se relaciona com duas dificuldades: a dificuldade dos alunos se expressarem por meio do desenho manual e, por decorrência, a forte pressão para que se libere o uso dos computadores nas disciplinas de projeto.

A primeira tem raízes relativamente antigas. Isso acontece por causa da pouca importância ou inexistência do ensino de desenho em suas diferentes modalidades, especialmente geometria, perspectiva e geometria descritiva associada com a progressiva redução da carga horária e do número de disciplinas de desenho em suas diferentes modalidades. A segunda indica o fortalecimento do movimento para transformar a universidade em uma instituição destinada basicamente a atender às demandas do mercado. $\mathrm{E} 0$ mercado, pelo menos no Rio de Janeiro, demanda estagiários com domínio de CAD, SketchUp e Photoshop, com pequenas variações.

Entre os alunos que estagiam, por sua vez, cresce o número dos que faltam, chegam atrasados ou saem mais cedo das minhas aulas em função dos estágios. Muitos deles são portadores de tendinite, em alguns já é crônica.

Retornando no tempo, é evidente a semelhança com o processo de separação das atividades de concepção e construção provocado por Brunelleschi no início do século XIV. Ao conceber o projeto como sistema de representação sobre um plano bidimensional, Brunelleschi transforma radicalmente a atividade do arquiteto.

A partir de então, o arquiteto deixa de se ocupar da função de integrar um conjunto de diversos ofícios especializados em diferentes atividades; deixa de arbitrar as intermináveis rivalidades e conflitos entre os diversos profissionais e passa a responder pelo projeto e pela escolha da técnica a ser utilizada em sua execução. Com isso, a autonomia dos seus executores é reduzida e modifica-se toda divisão técnica e social do trabalho.

Meio século depois, Alberti busca conciliar vontade com razão e propõe um sistema de harmonia e clareza matemática com vistas à elaboração de um plano inteligível e equilibrado com base em "uma regra maravilhosa e precisa” (ALBERTI apud BOUTINET, 2002, p. 37). Com Alberti o projeto passa a desempenhar o papel de norma para sua execução.

Mas a transição não é simples nem pacífica. Diversos arquitetos seguem lutando para manter as antigas práticas. Michelangelo, por exemplo, 
entende a construção como um processo que se auto-organiza na medida em que avança em conjunto com uma maquete construída no canteiro e atribui ao desenho um papel secundário. Passados mais de quinhentos anos ainda existem defensores da indissociabilidade entre concepção e construção. E assim, repentinamente, me descobri um arquiteto pré-renascentista!

\section{DISCUSSÃO}

Ao voltar para a atualidade, que se caracteriza pelo desenvolvimento e disseminação da plataforma CAD (Computer-Aided Design), dos modelos 3D e, mais recentemente, da plataforma BIM (Building Information Modeling), pego carona na resposta de Renzo Piano à pergunta formulada por Bianca Antunes (2011, p. 6): “Os arquitetos não serão mais artistas, mas operadores de um software? Piano - é preciso ser muito tolo para deixar-se enganar por um computador... nosso ofício se situa na encruzilhada entre técnica e arte.”

Essa resposta despertou em mim a curiosidade sobre o processo de projeto de Piano. Também me interessei pelo processo de projeto de Frank Gehry, em torno do qual circulam diversas histórias e mitos. Para minha surpresa, Piano e Gehry iniciam seus projetos como um processo analógico, e segundo Dushanov (2015), arquiteto responsável pelo projeto Arena do Morro, o mesmo acontece com o escritório Herzog \& de Meuron, que prioriza o uso de modelos tridimensionais físicos (maquetes).

Renzo Piano começa com alguns croquis que logo são transformados em desenhos. Na medida em que os croquis vão sendo desenvolvidos, ele parte para a construção de uma maquete "para então chegar à realidade - vamos ao espaço em questão -, voltando mais uma vez ao desenho. Estabelecemos uma espécie de circularidade entre o desenho e a concretização e da volta novamente ao desenho [...] fazer e refazer mais uma vez.” (PIANO apud SENNETT, 2009, p. 52). O processo de Frank Gehry, um arquiteto que confia na intuição (RAUTERBERG, 2009) inicia com um conjunto de croquis seguidos de modelos, que são discutidos com sua equipe de projeto. A seguir os modelos são manipulados e deformados até chegar a um resultado satisfatório. Uma vez aprovado, o modelo é fotografado e vetorizado para gerar as bases dos desenhos digitalizados. Ambos misturam processo-eproduto, analógico-e-digital; em lugar de confrontar ou tomar partido, eles os misturam. Na conferência de encerramento do VII Seminário Projetar em Natal (RN), o arquiteto Tomislav Dushanov, responsável pelo projeto da Arena do Morro, complexo multicultural e ginásio poliesportivo inaugurado em 2015 na comunidade Mãe Luiza em Natal (RN), enfatiza a importância das maquetes de estudo - por ele denominadas mock-ups - nos trabalhos do escritório. Dushanov também recomenda que as escolas de arquitetura retomem a prática das maquetes físicas de estudo, em detrimento da modelagem virtual.

O fato de arquitetos relacionados com inovação e novas tecnologias começarem seus projetos com croquis desenhados ou com modelos físicos tridimensionais e o reconhecimento de Piano (apud SENNET 2009) de que "nosso ofício se situa em uma encruzilhada entre arte e técnica" suscitou uma pergunta inevitável: se arquitetos como Piano, Gehry e Herzog \& de Meuron trabalham assim, porque em nossas escolas abandonamos os croquis e maquetes de estudo e consentimos ou estimulamos a substituição do desenho manual pelo desenho no computador e das maquetes físicas pelas virtuais? Seremos mais adiantados do que eles, ou se trata de uma mera ânsia tupiniquin pela novidade?

Há quem acredite que se trata de um problema relacionado com a transição da geração de "nativos analógicos" para a de "nativos digitais" (MONTEIRO, 2010) ou "geração superficial” (CARR, 2011). Enquanto as coisas não ficam mais claras, prefiro seguir os argumentos de Gregory Bateson. 
A possibilidade de abandonarmos ou atrofiarmos em demasia a linguagem analógica é preocupante, uma vez que implica abrir mão de nossa subjetividade e, por decorrência, de nossa humanidade. Assim como a possibilidade de, como os replicantes do filme Blade Runner de Ridley Scott (1982) ${ }^{1}$, as máquinas se tornarem capazes de lidar e compreender a linguagem analógica, bem como aprender a lidar com as emoções e ambiguidades. Entre a possibilidade de desumanizar os humanos e humanizar as máquinas, penso que o melhor e mais prudente seria nos ocuparmos de humanizar os humanos, de aprimorar as máquinas e aprendermos - em lugar de depender - a conviver em harmomia com elas. O mesmo se aplica com a natureza. Esse é o novo estatuto do coletivo proposto pelos adeptos dos estudos de ciência, tecnologia e sociedade (CTS)2

Voltando para o campo da arquitetura, a situação ainda está confusa a ponto de nos deixar atônitos. Nem bem a plataforma CAD se firmou e já começa a surgir um movimento em prol de sua substituição pela plataforma BIM.

Para Gabriela Celani, a disseminação da plataforma BIM não se resume a uma substituição de tecnologia; ela possibilita uma "mudança cultural do desenho 2D pelo 3D, ou da dimensão fixa para a chamada paramétrica" (CELANI, 2011, p. 17) com consequências diretas no ensino de desenho e de projeto. Sua adoção resulta em um complexo rearranjo das atividades de projeto, especialmente as relacionadas com projetos de geometria complexa ou com a coordenação de projetos considerando todo seu ciclo de produção e uso. Será o BIM o Brunelleschi do século XXI? Segundo Gabriel Rheingantz, arquiteto com prática e domínio das plataformas CAD e BIM, este último é uma espécie de Lego digital.

Nessa superposição de mudanças de cultura, as dificuldades e discussões relacionadas com a plataforma BIM também acontecem com a plataforma CAD. Em termos práticos, a maioria dos escritórios utiliza apenas parte dos recursos disponíveis na plataforma CAD como ferramenta de desenho em 2D: substitui-se o desenho manual pelo digital; troca-se a prancheta pelo computador.

Apesar das dificuldades naturais decorrentes de todo processo envolvendo mudança de cultura, a eficácia e a vantagem das plataformas CAD e BIM em projetos de grande porte ou grande complexidade são inegáveis, além de irreversíveis. Mas em países em desenvolvimento, em que os contrastes são evidentes e a maioria da população vive em condições de simples sobrevivência, essas vantagens precisam ser mais cuidadosamente ponderadas.

Mas não é a discussão sobre as vantagens e desvantagens do uso do computador em projetos que me interessa discutir neste artigo. Essa é apenas a superfície de um problema bem mais profundo. Para compreendêlo, é preciso mergulhar no entendimento da relação entre os processos analógico e digital como um problema de comunicação, uma vez que o projeto é, por excelência, uma linguagem de comunicação dos arquitetos com os proprietários, construtores e usuários.

Para esse mergulho, recorro a um pensador que se dedicou às "coisas vivas" e aos problemas sobre o belo; um dos mais importantes e singulares estudiosos da comunicação humana e seus paradoxos: Gregory Bateson e seu pressuposto da impossibilidade de não comunicar - estamos comunicando mesmo quando estamos em silêncio (BATESON apud SCHROEDER, 2010).

Com roteiro de Hampton Fancher e David Peoples, inspirado no livro Do Androids Dream of Electric Sheep? de Philip K. Dick.

Cf. Cukierman; Teixeira e Prikladnicki (2007). As modificações na forma e na substância do controle, da participação e da coesão social produzidas pelas novas tecnologias também são modificadas pela experiência social, de sorte que o técnico e o social constituem um movimento de "comodificação" concomitante social e técnico - ou sociotécnico. A abordagem sociotécnica possibilita contornar os impasses decorrentes da separação entre o técnico e o social e, no caso da arquitetura, também o estético. Como o técnico, o social e o estético passam a ser percebidos a partir de seu movimento de "comodificação", o olhar sociotécnico busca apreender o ambiente construído como um mesmo e indivisível tecido sem fragmentá-lo em "fatores técnicos" de um lado, e "fatores não-técnicos" - estéticos e sociais ou humanos, organizacionais, éticos, políticos, sociais etc. - de outro. 
Seu estatuto foi eternizado em um de seus metadiálogos: Porque os franceses mexem muito os braços?

as mensagens que trocamos por gestos não são de fato as mesmas que as traduções desses gestos em palavras [...] a linguagem é primeiro, e para além de tudo o mais, um sistema de gestos. Os animais só têm gestos e tons de voz - as palavras foram inventadas mais tarde. (BATESON, 1989, p. 24-26)

Segundo Bateson, nós humanos utilizamos duas maneiras diferentes, mas complementares, para nos referirmos aos objetos: por semelhança autoexplicativa - por meio de gestos, mímicas, desenhos - equivalente ao entendimento de analógico, ou por nomes ou palavras - sinais arbitrários e abstratos correspondentes à sintaxe lógica da linguagem - equivalente ao entendimento de digital.

A comunicação ou linguagem analógica, mais ambígua e imprecisa, está associada às relações, às artes e às subjetividades. Costumamos utilizá-la para definir a natureza das nossas relações ou o nosso jeito de ser e estar no mundo com nossas emoções e afetos. Quando a utilizamos, recorremos a vocalizações, gestos, sinais de humor e desenhos. A comunicação ou linguagem digital, mais precisa e abstrata, está associada ao conhecimento científico e tecnológico. Costumamos utilizá-la para fazer referência aos objetos e relações por um nome ou palavra. Mas a linguagem digital é incapaz de lidar com o significado dos gestos e da comunicação não verbal. "O silêncio será sempre da palavra, nunca da emoção." (SCHROEDER, 2010, p. 190). Como as duas têm suas limitações, em nossas comunicações combinamos as duas linguagens, ora como emissores, ora como receptores; estamos constantemente traduzindo uma mensagem analógica para digital e vice-versa.

Como toda tradução entre processos analógicos e digitais produz ruídos, ela será sempre imperfeita, portadora de algum tipo de ruído, conflito ou perda. Segundo Bateson, toda troca de mensagens produz um paradoxo ou uma relação de duplo vínculo: um processo contínuo e dinâmico de troca de papéis no qual ambos atuam como emissor e como receptor. Os papéis oscilam continuamente em função das circunstâncias em que se processa a troca. Quando perdemos a capacidade de optar por descobrir exatamente o que alguém ou algo está querendo nos dizer, estamos perdendo nossa capacidade de lidar com os dois modos de linguagem (digital e analógica) ao mesmo tempo.

O paradoxo fará parte da troca de mensagens sempre que precisamos da lógica em nossas relações envolvendo as palavras (digital) e as emoções (analógico). Quando nos comunicamos, especialmente no humor e na arte, dificilmente nos limitamos ao uso de apenas uma linguagem.

Esse é o caso da arquitetura. Na medida em que o processo de digitalização avança, estamos perdendo a capacidade de utilizar a linguagem analógica. Aumenta nossa dificuldade de receber, elaborar e retornar mensagens. No cotidiano dos escritórios e laboratórios de projetos, as interações verbais, tradicionais nos tempos em que o desenho era elaborado à mão, foram praticamente eliminadas, assim como os desenhistas.

Precisamos “comunicar-nos" com nossas máquinas, definir os comandos que permitam que elas interpretem e realizem as operações que irão resultar em uma resposta: um texto, um desenho, uma operação matemática. Nossas cabeças e mãos precisam comunicar-se e interagir com dois novos atores: o computador e o software. Mas a comunicação com os computadores atuais está restrita à modalidade digital, uma vez que eles ainda não têm capacidade para lidar com a linguagem analógica. Com isso estamos reduzindo nossa aptidão para o uso da linguagem analógica. Cada vez ficamos mais hábeis na linguagem digital. "Dependentes de uma lógica digital, paralisamos frente a qualquer ambiguidade” (SCHROEDER, 
2010, p. 196). Ansiamos por respostas lógicas e precisas: sim ou não, certo ou errado, 0 ou 1.

Há quem considere essa dificuldade consequência das demandas do mundo profissional da precisão e da eficiência... Mas que tipo de eficiência justifica abrir mão de nossa humanidade?

Mas a complexidade e dinâmica do projeto - e do seu ensino - e da construção ainda demandam e dependem da linguagem analógica, bem mais adequada para lidar com as ambiguidades e complexidades que caracterizam os dois processos. Quando o processo se limita ao projeto, a substituição do processo analógico pelo digital torna-se menos problemática senão irreversível ou inevitável. Mas ainda acredito na possibilidade de mudar de curso para recuperar a tradição pré-renascentista, ainda "no presente" de alguns arquitetos, especialmente aqueles que vivem e trabalham nas pequenas cidades do interior do Brasil. Acredito na possibilidade de ampliar nossos restritos horizontes de modo a incorporar em nossa clientela a maioria da população brasileira que paga nossos salários e banca a gratuidade da formação dos nossos estudantes. Nesse caso, será conveniente - senão necessário - rever o movimento de atrofia da linguagem analógica em detrimento da digital.

Se descuidarmos da importância do desenho como linguagem de comunicação analógica-e-digital entre arquiteto-construtor-cliente-usuário, provavelmente estaremos construindo uma barreira comunicativa entre alguns desses segmentos, especialmente quando se tratar de projetos de autoconstrução ou tradicionais. Como resultado desse gap comunicacional, pode acontecer um estreitamento ainda maior da população beneficiada por nosso conhecimento.

Há alguns anos vivenciei uma experiência ilustrativa do que acabo de falar. Em meados dos anos 1990, comprei e reformei um apartamento na Praia de Botafogo. Desenhei e detalhei todo o projeto, especialmente banheiros e cozinha. Contratei um empreiteiro bem recomendado, mas com a obra iniciada, descobri que, por ser analfabeto, não sabia ler os desenhos. Para nos comunicarmos passei a "desenhar" os detalhes mais complexos da obra com giz de alfaiate ou com uma haste metálica diretamente no piso e nas paredes em escala 1:1. O resultado final ficou muito bom, e os desenhos, intactos.

A dificuldade de lidar com as tecnologias "obsoletas" e com a linguagem "analógica" foi abordada com inteligência e ironia por Clint Eastwood (2000) no filme Caubóis do Espaço ${ }^{3}$ O filme sinaliza a possibilidade de problemas dessa natureza acontecerem no futuro e a dificuldade da "geração digital" lidar com a ambiguidade das questões analógicas.

Acredito que a chave do dilema entre processo digital ou analógico na arquitetura e no ensino de projeto esteja no equilíbrio entre as duas linguagens, que não são contraditórias. Elas são complementares. Precisamos das duas.

Devemos buscar alternativas para recuperar nossa capacidade de lidar com as ambiguidades de um mundo em movimento que valoriza e multiplica as diferenças; buscar um equilíbrio entre as linguagens gráfica e digital, que nos permita recuperar nossa habilidade em lidar com as ambiguidades e com a diferença, como a "habitação popular" que sugere que as demais sejam impopulares.

Considerando o grau de instrução e os níveis de renda da maioria da população brasileira, a disseminação da linguagem digital pode dificultar a comunicação dos arquitetos, demandando um contingente de intermediários, aumentando ainda mais o nível de ruído na comunicação, com reflexos previsíveis e indesejáveis no resultado final. 
Minha experiência como professor de Projeto de Arquitetura indica que a maior parte dos projetos dos alunos de graduação termina no estudo preliminar. Poucos chegam ao anteprojeto. Prevalecem as etapas iniciais de concepção em que a linguagem analógica e o desenho à mão livre são importantes, senão prevalentes.

As evidências até aqui apresentadas indicam que o confronto analógico $\mathrm{X}$ digital é um falso dilema; trata-se de um problema que não se resume a uma simples substituição de um processo por outro. Conforme sugere Bateson, as linguagens analógica e digital não são contraditórias, elas são complementares. Assim, o dilema se converte em um problema de linguagem e comunicação que não se reduz às questões técnicas ou funcionais. Ele também é cognitivo e cultural.

\section{CAMINHOS E HORIZONTES POSSÍVEIS}

Estou convicto de que o dilema apresentado é um problema resultante de crenças e atitudes (BASTOS; ZEIN, 2010, p. 239). Para superá-lo, basta reunir algumas recomendações do pensamento complexo de Morin (2000), como reformar nossas cabeças; mudar nossos pensamentos e atitudes; deixar de isolar os objetos de seu contexto, dissociar os problemas, separar os conhecimentos; reunir os saberes que estão separados, fragmentados ou compartimentados em disciplinas (MORIN, 2000), com outras recomendações da abordagem sociotécnica, como mudar o enquadramento no qual o técnico, o social e o estético configuram um mesmo e divisível tecido e constituem um movimento de "comodificação" (CUKIERMAN; TEIXEIRA; PRIKLADNICKI, 2007).

Penso que ambas são condições necessárias para que um conhecimento seja pertinente; "capaz de situar qualquer informação em seu contexto, [...] no conjunto em que está inscrita” (MORIN, 2000, p. 15). Ao aplicarmos a proposição de reunir os saberes separados, transformamos a concepção de projeto ser analógico ou digital em um falso dilema. Por sua vez, o caminho a ser seguido, especialmente nos ateliês de projeto das escolas de arquitetura, parece bastante simples: basta (a) substituir a conjunção "ou" pela conjunção aditiva "e"; e (b) eliminar a interrogação final. Com isso, o antigo (e falso) dilema se transforma em uma promissora possibilidade: concepção e ensino de projeto: processo analógico-e-digital.

\section{AGRADECIMENTOS}

O autor agradece o apoio do CNPq [Bolsa de Produtividade - processo 300947/2013-5 - e Edital Universal - processo 475549/2012-0] e da Capes [Bolsa Professor Visitante Nacional Sênior - processo nº 23038009722201321].

\section{REFERÊNCIAS}

ANTUNES, B. Entre a arte e a tecnologia. Arquitetura e Urbanismo, n. 208, p. 6, jul. 2011.

BASTOS, M. A. J.; ZEIN, R. V. Brasil arquiteturas após 1950. São Paulo: Perspectiva, 2010.

BATESON, G. Mind and nature. Nova lorque: Dutton, 1979.

BATESON, G. Metadiálogos. Lisboa: Gradiva, 1989.
BOUTINET, J.-P. Antropologia do projeto Porto Alegre: Artmed, 2002

CARR, N. A geração superficial: o que a internet está fazendo com os nossos cérebros. Rio de Janeiro: Agir, 2011.

CELANI, G. Fato \& Opinião. Revista Arquitetura e Urbanismo, n. 208, p. 17, jul. 2011.

CUKIERMAN, H.; TEIXEIRA, C.; PRIKLADNICKI, R. Um olhar sociotécnico sobre a engenharia de software. Revista de 
Informática Teórica e Aplicada, v. 14, n. 2 , p. 199-219, 2007

DUSHANOV, T. Uma visão sobre Mãe Luiza: estudo, projeto, construção e uso. In: CONFERENCIA DE ENCERRAMENTO DO VII PROJETAR - 2015: ORIGINALIDADE, CRIATIVIDADE E INOVAÇÃO NO PROJETO CONTEMPORÂNEO: ENSINO, PESQUISA E PRÁTICA, 2015, Natal. Anais... Natal: UFRN/ UFPB, 2015.

MONTEIRO, E. Nativos digitais já estão dominando o mundo e transformando a forma como o ser humano se comunica. Extra. Disponível em: <http://extra.globo. $\mathrm{com} /$ noticias/saude-e-ciencia/nativosdigitais-ja-estao-dominando-mundotransformando-forma-como-ser-humano- se-comunica-284984.html>. Acesso em: 14 ago. 2010

MORIN, E. A cabeça bem-feita: repensar a reforma, reformar o pensamento. Rio de Janeiro: Bertand Brasil, 2000.

PESSOA, F. Obra poética. Rio de Janeiro: Nova Aguilar, 2001.

RAUTERBERG, H. Entrevistas com arquitetos. Rio de Janeiro: Viana \& Mosley, 2009.

SCHROEDER, V. Híbridos e paradoxais. In: FERREIRA, A. A. L.; FREIRE, L.; MORAES, M.; ARENDT, R. (Orgs.). Teoria ator-rede e psicologia. Rio de Janeiro: NAU, 2010. p. 180-198.

SENNETT, R. 0 artífice. Rio de Janeiro: Record, 2009. 